\title{
Preface to Special Collection: Reformation, Transformation and Change Agency
}

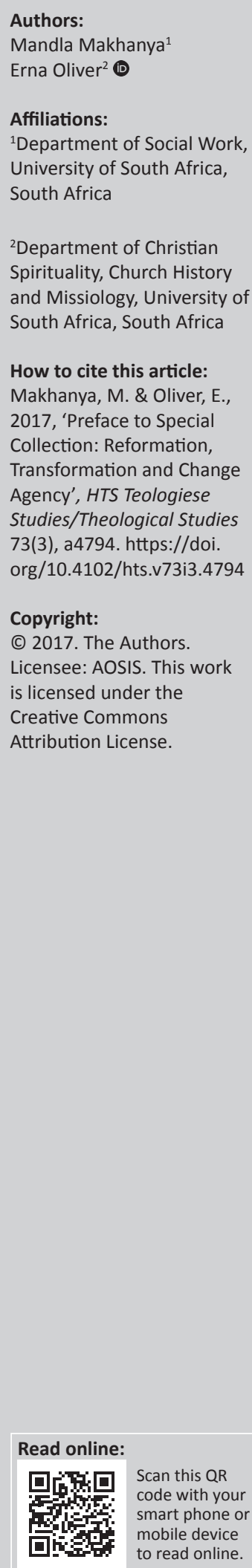

The speed with which things change makes it clear that we are at a turning point in history. The change that society is experiencing is not an event that will soon stop and allow us to settle down. It is a complex, accelerating process with no defined destination and it often seems as if we are unable to manage it; that society is experiencing a change speed wobble. To counter this, we need to develop a mindset that is receptive to change, transformation and development. We should embrace the energy, excitement and increased productivity that allow change to enable us to rediscover our sense of adventure, inspiration and purpose for living. And we must remember that the current changes are not the first or the most radical in the history of the development of society.

The earliest Christians drew attention to themselves by their radical behaviour as agents of change that stunned and confused other people. The command for love caused a watershed, disruptive change to society and transformed millions of lives. Centuries later, the Reformation of the Christian religion again brought major change to society through its revival and paradigm shifts, and opened doors to new ways of thinking and living. The 500th celebration of this event in 2017, together with the shift towards the establishment of the network society, coincides to call for reflection and renewed actions as the world and the Christian religion are once again in need of a dramatic makeover that can provide solutions for social problems, and inspire new approaches to transform people's lives.

The term 'reformation' originates from the Latin reformatio, meaning 'to clean from corruption and inefficiency'. The term was also used later to refer to an attempt to perform any seemingly impossible task; however, in the last two centuries, its use became limited and often linked only to the 16th-century church reforms. The term that since the year 2000 has been increasingly used in its place in society is 'transformation', which also derives from Latin (transformatio), meaning 'to change' or 'to shape'. One of the possible meanings attached to this term is a marked or radical change in appearance or character, usually for the better. This is also what is needed in terms of the Christian religion in the 21st-century society.

This publication is a first probe initiated by theological educators at the University of South Africa towards stimulating thoughts and actions regarding positive change and transformation leading up to the Reformation celebrations of 2017. Effective change depends on a clear message and a sense of urgency. It requires engagement and ownership and must be driven by a heartfelt belief and passion to deliver on all aspects of our multifaceted tasks. We realise that we can no longer rest on our illustrious history and legacy at this point in time. It is time to develop new paradigms, new ways of thinking and new approaches to bring about positive change that will entail structural changes and transformation. Being a Christian cannot be about rules and rites. It should be about transformative change guided by a clear and focused vision. Theology and Christianity must be about developing transferable capabilities, leadership skills and the willingness to take responsibility and initiative to bring about positive change to a broken and desperate world.

Acknowledgement and deepest appreciation go to Willem Oliver for his unstoppable enthusiasm and commitment to develop the Change Agent Project in the Discipline of Church History at the University of South Africa. This book is one of the first fruits from the project and its publication would not have been possible without his dedication, persistence and hard work. Apart from initiating the book project, he also took full responsibility of the administration of both the book and the 500-year celebration of the Reformation event to be held at the University of South Africa on 31 October 2017.

Also gratitude and appreciation go to the authors and contributors who, despite their other commitments, kept to the due dates and worked hard to make this publication such an inspiring 
work that we believe would encourage others to become positive agents of change in their communities towards the betterment of society through the light of our faith in Christ our Saviour.
In addition to contributing the editorial introduction to this publication, the Vise-Chancellor and Prinsipal of the University of South Africa, Prof Mandla Makhanya supported the Change Agents Project in all its facets during the past two years. 